\title{
Research on the Evaluation of Information Security Management under Intuitionisitc Fuzzy Environment
}

\author{
LI Feng-Quan \\ College of technology, Xi'an International University, 710077, Xi'an Shaanxi \\ China \\ lifengquan@xaiu.edu.cn
}

\begin{abstract}
With the rapid development of computer technology and information technology, information has been a new asset of the enterprise and played more and more important role. How to protect information security is the problem that all companies need to solve together. In this paper, we propose a novel method to evaluate the enterprise's information security management under intuitionisitc fuzzy environment. The intuitionistic fuzzy set which considers not only membership and non-membership, but also hesitancy can express the decision maker's preferences more precise. The extended TOPSIS approach with correlation coefficient instead of distance measure is introduced in the procedure of decision making. Finally, the application and comparison analysis are demonstrated to verify validity and reliability of the method.
\end{abstract}

Keywords: information security management, Intuitionistic fuzzy set, TOPSIS, correlation coefficient

\section{Introduction}

With the growing spread of communication media and the exponential increase of electronic storage and transmission of information, the need for information security has risen to high levels. Systemized and standardized are main trend in the development of information security management. The setting-up of information security management system is the effective way to guarantee information security. The evaluation of information security management has received more and more attention. Li [1] introduced D-S evidence theory to evaluate the capacity of information security management. The characteristics of information security management were analyzed and based on the PDRR, the new information security management model was proposed. Huang [2] centered the study on the information security management of the personal data protection to promote their standardization. Bellone [3] proposed some specific operational plans and approaches to assess information security management. To evaluate a set of alternatives, the decision maker should give preferences on each attribute for each alternative. However, it is difficult to express the decision maker's preferences accurately. Fuzzy logic and fuzzy set are popular when handling imperfect, vague or imprecise preferences.

Since fuzzy set was proposed by Zadeh [4], it has been successfully used for handling fuzzy decision making problems. The main characteristic of fuzzy sets is that: the membership function assigns to each element $x$ in a universe of discourse $X$ a membership in interval $[0,1]$ and the non-membership degree equals one minus the membership degree. Fruitful research results of fuzzy sets have been achieved in many different fields $[5,6]$. In application, however, the information combines not only evidence for $x$ or evidence against $x$, but also uncertainty. Because of the lack of knowledge, the decision maker does not know whether evidence for $x$ or not.

In order to solve this problem, Atanassov [7] introduced the concept of intuitionistic 
fuzzy set (IFS), which as a generalization of the concept of fuzzy set considers the membership degree, the non-membership degree and the uncertain degree. Meanwhile, Atanassov [8] defined some operational laws of intuitionistic fuzzy sets. The intuitionistic fuzzy set has received more and more attention since its appearance [9-11]. Szmidt and Kacprzyk [12] used intuitionistic fuzzy sets to solve group decision making problems. Xu and Yager [13] proposed some aggregation operators based on intuitionistic fuzzy sets, and applied them to multiple attribute decision making. $\mathrm{Xu}$ [14] developed some intuitionistic fuzzy aggregation operators, including the intuitionistic fuzzy weighted averaging operator, intuitionistic fuzzy ordered weighted averaging operator, and intuitionistic fuzzy hybrid aggregation operator, which can be used to aggregate intuitionistic fuzzy information. In [15], an automotive company is desired to select the most appropriate supplier for one of the key elements in its manufacturing process. It is difficult how to select the best supplier from five candidates. Meanwhile, four attributes should be considered.

TOPSIS(technique for order preference by similarity to an ideal), proposed by Hwang and Yoon [16], whose basic principle is to choose the alternative with the shortest distance from the positive ideal solution(PIS) and the farthest distance from the negative ideal solution(NIS). It has gained a lot of attention. Manish Agarwal [17] compared Choquet integral with TOPSIS in terms of solving the supplier selection problem under fuzzy environment. TOPSIS was applied to financial investment in advanced manufacturing systems [18]. G. R. Jahanshahloo [19] extended the TOPSIS method to decision-making problems with fuzzy data, where the rating of each alternative and the weight of each criterion are expressed in triangular fuzzy numbers.

In this paper, motivated by the mentioned method of intuitionistic fuzzy set, we propose a new TOPSIS method with correlation coefficient. In traditional TOPSIS approach, distance measure is used to measure deviation of alternatives and the positive ideal solution (PIS) or the negative ideal solution (NIS). In the new TOPSIS approach, we define the weighted correlation coefficient to measure the correlation of two intuitionistic sets instead of distance measure. It can provide more choice to make best decision. Correlation indicates how well two variable move together in a linear fashion [20]. As an important content in fuzzy mathematics, correlation between fuzzy sets has gained much attention [21]. Przemyslaw Grzegorzewski introduced Kendall's correlation coefficient for fuzzy preference [22]. Ye [23] used correlation coefficient to intuitionistic, interval-valued intuitionistic fuzzy multiple attribute decision making. The characteristics of the weighted correlation coefficient including commutativity, boundary, and reflexivity are demonstrated and proven. Similar to traditional TOPSIS approach, the correlation coefficient is used to compute the closeness coefficient to rank all the alternatives. The greater the closeness coefficient is, the better the alternative will be.

The main contribution of this paper includes the following: (1) the design of new evaluation model of information security management under intuitionistic fuzzy environment; (2) the introduction of weighted correlation coefficient of intuitionistic fuzzy set; (3) the creation of new TOPSIS approach with correlation coefficient; and(4) the practical application of the new method.

The rest of this paper is organized as follows. In Section 2, we review some basic concepts related to intuitionistic fuzzy set. Section 3 introduces the weighted correlation coefficient under intuitionistic fuzzy environment. In Section 4, a new TOPSIS approach is proposed. In Section 5, an evaluation problem of information security management is investigated to demonstrate the proposed method, and verify its validity and applicability. Finally, Section 6 concludes this paper.

\section{Preliminaries}

Intuitionistic fuzzy set which generates the concept of Zadeh's fuzzy set is 
characterized by a membership degree, a non-membership degree and a hesitancy degree to describe uncertainty and vagueness more proper. In this section, we review some concepts of intuitionistic fuzzy set.

Definition 1 [7] Let $X$ be an ordinary finite non-empty set. An intuitionisitc fuzzy set in $X$ is an expression $A$ given by

$$
A=\left\{\left\langle x, u_{A}(x), v_{A}(x)\right\rangle \mid x \in X\right\}
$$

Where $u_{A}: X \rightarrow[0,1]$ denotes the degree of membership and $v_{A}: X \rightarrow[0,1]$ denotes the degree of non-membership with the condition: $0 \leq u_{A}+v_{A} \leq 1$, for all $x$ in $X$.

For each intuitionistic fuzzy set $A$ in $X$, if the amount

$$
\pi_{A}(x)=1-u_{A}(x)-v_{A}(x), \forall x \in X
$$

Then $\pi_{A}(x)$ is called the degree of indeterminacy of $x$ to $A$. Especially, If

$$
\pi_{A}(x)=1-u_{A}(x)-v_{A}(x)=0, \forall x \in X
$$

Then the intuitionisitc fuzzy set $A$ is reduced to a fuzzy set. For computational convenience, in this paper, we call $\left(u_{A}(x), v_{A}(x)\right)$ an intuitionistic fuzzy value.

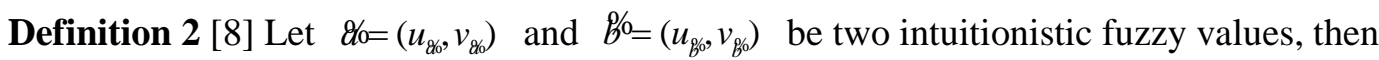

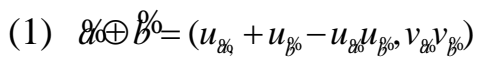

(2) $\lambda \ddot{g} \sigma=\left(1-\left(1-u_{g i}\right)^{\lambda},\left(v_{g d}\right)^{\lambda}\right), \lambda>0$

Definition 3 [13] Given two intuitionistic fuzzy values $a$ and $b$, the following operations are valid:

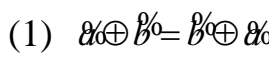

(2) $\lambda_{1}(B \notin B)=\lambda_{1} d \leftrightarrow \lambda_{1} b c$

(3) $\lambda_{1} \& \circledast \lambda_{2} \& \sigma=\left(\lambda_{1}+\lambda_{2}\right) B c$

\section{The Correlation Coefficient under Intuitionistic Fuzzy Environment}

Considering the operational characteristic of intuitionistic fuzzy set, we introduce the following correlation coefficients between intuitionistic fuzzy sets: the correlation coefficient and the weighted correlation coefficient.

Definition 4. (Gerstenkorn and Manko, 1991)Given two intuitionistic fuzzy sets $M=$ $\left\{\left\langle x, u_{M}(x), v_{M}(x)\right\rangle \mid x \in X\right\}$ and $N=\left\{\left\langle x, u_{N}(x), v_{N}(x)\right\rangle \mid x \in X\right\}$, the correlation coefficient between $M$ and $N$ is given as:

$$
\begin{gathered}
\rho_{I F}(M, N)=\frac{C(M, N)}{\sqrt{C(M, M)} \cdot \sqrt{C(N, N)}} \\
=\frac{\sum_{i=1}^{n}\left(u_{M}\left(x_{i}\right) u_{N}\left(x_{i}\right)+v_{M}\left(x_{i}\right) v_{N}\left(x_{i}\right)\right)}{\left\{\sum_{i=1}^{n}\left[u_{M}^{2}\left(x_{i}\right)+v_{M}^{2}\left(x_{i}\right)\right]\right\}^{\frac{1}{2}} \cdot\left\{\sum_{i=1}^{n}\left[u_{N}^{2}\left(x_{i}\right)+v_{N}^{2}\left(x_{i}\right)\right]\right\}^{\frac{1}{2}}}
\end{gathered}
$$

Definition 5. Given two intuitionistic fuzzy sets $M=\left\{\left\langle x, u_{M}(x), v_{M}(x)\right\rangle \mid x \in X\right\}$ and $N=$ $\left\{\left\langle x, u_{N}(x), v_{N}(x)\right\rangle \mid x \in X\right\}$, the weighted correlation coefficient between $M$ and $N$ is given as:

$$
\rho_{I F W}(M, N)=\frac{C(M, N)}{\sqrt{C(M, M)} \cdot \sqrt{C(N, N)}}
$$




$$
=\frac{\sum_{i=1}^{n} w_{i}\left(u_{M}\left(x_{i}\right) u_{N}\left(x_{i}\right)+v_{M}\left(x_{i}\right) v_{N}\left(x_{i}\right)\right)}{\left\{\sum_{i=1}^{n} w_{i}\left[u_{M}^{2}\left(x_{i}\right)+v_{M}^{2}\left(x_{i}\right)\right]\right\}^{\frac{1}{2}} \cdot\left\{\sum_{i=1}^{n} w_{i}\left[u_{N}^{2}\left(x_{i}\right)+v_{N}^{2}\left(x_{i}\right)\right]\right\}^{\frac{1}{2}}}
$$

Theorem1 Let $M$ and $N$ be two IFSs on a universe of discourse $X=\left\{x_{1}, x_{2}, \mathrm{~L}, x_{n}\right\}$, the correlation coefficient between $M$ and $N$ should satisfy the following properties:

(1) Commutativity

$$
\rho_{I F W}(M, N)=\rho_{I F W}(N, M)
$$

(2) Boundedness

$$
0 \leq \rho_{I F W}(M, N) \leq 1
$$

(3) Reflexivity

$$
\rho_{I F W}(M, N)=1, \text { if } M=N
$$

Proof.

(1) $\rho_{I F W}(M, N)=\frac{C(M, N)}{\sqrt{C(M, M)} \cdot \sqrt{C(N, N)}}$

$$
\begin{aligned}
& =\frac{\sum_{i=1}^{n} w_{i}\left(u_{M}\left(x_{i}\right) u_{N}\left(x_{i}\right)+v_{M}\left(x_{i}\right) v_{N}\left(x_{i}\right)\right)}{\left\{\sum_{i=1}^{n} w_{i}\left[u_{M}^{2}\left(x_{i}\right)+v_{M}^{2}\left(x_{i}\right)\right]\right\}^{\frac{1}{2}} \cdot\left\{\sum_{i=1}^{n} w_{i}\left[u_{N}^{2}\left(x_{i}\right)+v_{N}^{2}\left(x_{i}\right)\right]\right\}^{\frac{1}{2}}} \\
& =\frac{\sum_{i=1}^{n} w_{i}\left(u_{N}\left(x_{i}\right) u_{M}\left(x_{i}\right)+v_{N}\left(x_{i}\right) v_{M}\left(x_{i}\right)\right)}{\left\{\sum_{i=1}^{n} w_{i}\left[u_{N}^{2}\left(x_{i}\right)+v_{N}^{2}\left(x_{i}\right)\right]\right\}^{\frac{1}{2}} \cdot\left\{\sum_{i=1}^{n} w_{i}\left[u_{M}^{2}\left(x_{i}\right)+v_{M}^{2}\left(x_{i}\right)\right]\right\}^{\frac{1}{2}}}
\end{aligned}
$$

$=\rho_{I F W}(N, M)$

The inequality $\rho_{I F W}(M, N) \geq 0$ is obvious. Below let us prove $\rho_{I F W}(M, N) \leq 1$;

$$
\begin{gathered}
C(M, N)=\sum_{i=1}^{n} w_{i}\left(u_{N}\left(x_{i}\right) u_{M}\left(x_{i}\right)+v_{N}\left(x_{i}\right) v_{M}\left(x_{i}\right)\right) \\
=w_{1} u_{M}\left(x_{1}\right) u_{N}\left(x_{1}\right)+\mathrm{L}+w_{n} u_{M}\left(x_{n}\right) u_{N}\left(x_{n}\right)+w_{1} v_{M}\left(x_{1}\right) v_{N}\left(x_{1}\right)+\mathrm{L}+w_{n} v_{M}\left(x_{n}\right) v_{N}\left(x_{n}\right) \\
=\sqrt{w_{1}} u_{M}\left(x_{1}\right) \sqrt{w_{1}} u_{N}\left(x_{1}\right)+\mathrm{L}+\sqrt{w_{n}} u_{M}\left(x_{n}\right) \sqrt{w_{n}} u_{N}\left(x_{n}\right)+ \\
+\sqrt{w_{1}} v_{M}\left(x_{1}\right) \sqrt{w_{1}} v_{N}\left(x_{1}\right)+\mathrm{L}+\sqrt{w_{n}} v_{M}\left(x_{n}\right) \sqrt{w_{n}} v_{N}\left(x_{n}\right)
\end{gathered}
$$

According to the Cauchy-Schwarz inequality:

$$
\left(x_{1} y_{1}+x_{2} y_{2}+\cdots+x_{n} y_{n}\right)^{2} \leq\left(x_{1}^{2}+x_{2}^{2}+\cdots+x_{n}^{2}\right) \cdot\left(x_{1}^{2}+x_{2}^{2}+\cdots+x_{n}^{2}\right)
$$

We can obtain:

$$
\begin{gathered}
(C(M, N))^{2} \leq\left(w_{1}\left(u_{M}\left(x_{1}\right)\right)^{2}+\mathrm{L}+w_{n}\left(u_{M}\left(x_{n}\right)\right)^{2}+w_{1}\left(v_{M}\left(x_{1}\right)\right)^{2}+\mathrm{L}+w_{n}\left(v_{M}\left(x_{n}\right)\right)^{2}\right) \\
\cdot\left(w_{1}\left(u_{N}\left(x_{1}\right)\right)^{2}+\mathrm{L}+w_{n}\left(u_{N}\left(x_{n}\right)\right)^{2}+w_{1}\left(v_{N}\left(x_{1}\right)\right)^{2}+\mathrm{L}+w_{n}\left(v_{N}\left(x_{n}\right)\right)^{2}\right) \\
=\left(w_{1}\left[\left(u_{M}\left(x_{1}\right)\right)^{2}+\left(v_{M}\left(x_{n}\right)\right)^{2}\right]+\mathrm{L}+w_{n}\left[\left(u_{M}\left(x_{n}\right)\right)^{2}+\left(v_{M}\left(x_{n}\right)\right)^{2}\right]\right) \\
\cdot\left(w_{1}\left[\left(u_{N}\left(x_{1}\right)\right)^{2}+\left(v_{N}\left(x_{n}\right)\right)^{2}\right]+\mathrm{L}+w_{n}\left[\left(u_{N}\left(x_{n}\right)\right)^{2}+\left(v_{N}\left(x_{n}\right)\right)^{2}\right]\right) \\
=\left\{\sum_{i=1}^{n} w_{i}\left[u_{N}^{2}\left(x_{i}\right)+v_{N}^{2}\left(x_{i}\right)\right]\right\} \cdot\left\{\sum_{i=1}^{n} w_{i}\left[u_{M}^{2}\left(x_{i}\right)+v_{M}^{2}\left(x_{i}\right)\right]\right\} \\
=C(M, M) \cdot C(N, N)
\end{gathered}
$$


Therefore

$$
\begin{aligned}
& (C(M, N))^{2} \leq C(M, M) \cdot C(N, N) \\
& C(M, N) \leq \sqrt{C(M, M) \cdot C(N, N)}
\end{aligned}
$$

Then

(3) if $M=N$,

$$
\rho_{I F W}(M, N)=\frac{C(M, N)}{\sqrt{C(M, M)} \cdot \sqrt{C(N, N)}} \leq 1
$$

$$
\rho_{I F W}(M, M)=\frac{C(M, M)}{\sqrt{C(M, M)} \cdot \sqrt{C(M, M)}}=1
$$

When $w_{i}=1 / n(\mathrm{i}=1,2, \mathrm{~L}, n)$, intuitionistic fuzzy weighted correlation coefficient reduces to intuitionistic fuzzy correlation coefficient.

\section{Decision Making Procedure based on TOPSIS Approach}

In traditional TOPSIS approach, the deviation between the alternative and the positive ideal solution or the negative ideal solution is measured by distance. Its basic principle is to choose the alternative which has the smallest distance to the positive ideal solution and the biggest distance to the negative ideal solution.

In this section, we extend the TOPSIS with correlation coefficient instead of distance measure in the procedure of decision making problem. The proposed TOPSIS approach's basic principle is to choose the alternative which has the biggest value of correlation coefficient to the positive ideal solution and the smallest value of correlation coefficient to the negative ideal solution. The correlation is introduced to compare the alternative with the positive ideal solution or the negative ideal solution.

Under intuitionistic fuzzy environment, the intuitionistic fuzzy PIS, denoted by $A^{+}$, and the intuitionistic fuzzy NIS, denoted by $A^{-}$can be defined as follows:

$$
\begin{aligned}
& A^{+}=\left\{x_{j}, \max _{i}\left\langle u\left(x_{j}\right)\right\rangle, \min _{i}\left\langle v\left(x_{j}\right)\right\rangle \mid j=1,2, \mathrm{~L}, n\right\} \\
& A^{-}=\left\{x_{j}, \operatorname{mi}_{i} \mathrm{i}\left\langle\begin{array}{lll}
\mathrm{n} u & (x\rangle))_{i} m\langle a x
\end{array}\right\rangle\right)(x \Rightarrow \quad j \mathrm{~L} 1,\}^{2}
\end{aligned}
$$

In order to simplify, we use the Eq. (6) and Eq. (7) instead of the Eq. (4) and Eq. (5).

$$
\begin{aligned}
A^{+} & =\left\{x_{j}, 1, \mid 0 j \quad 1 \mathrm{~L}, 2,\right\}_{r} \\
A^{-} & =\left\{x_{j}, 0,1 \mid j=1,2, \mathrm{~L}, n\right\}
\end{aligned}
$$

The relative closeness coefficient of an alternative $A_{i}$ with respect to the hesitant intuitionisic fuzzy PIS $A^{+}$is expressed as follows:

$$
C C_{i}=\frac{\rho_{i}^{+}}{\rho_{i}^{+}+\rho_{i}^{-}}
$$

Where $0 \leq C C_{i} \leq 1, i=1,2, \ldots m$. Obviously, when an alternative is closer to the intuitionistic fuzzy PIS and farther from the intuitionistic fuzzy NIS, $C C_{i}$ will be closer to 1 . Hence, according to the closeness coefficient $C C_{i}$, the ranking-order of all alternatives can be determined and the best alternative can be found.

According to the above models, we can present a novel approach to solve MADM problem, where attribute values take the form of intuitionistic fuzzy information. The approach involves the following step:

Step 1. For a MADM problem, we construct the decision matrix $D=\left[\mathscr{Z}_{i j}\right]_{m \times n}$, where all the arguments $\mathscr{Z}_{i j}(i=1,2, \ldots m ; j=1,2, \ldots n)$ are IFS, given by the DM. As for every alternative $a_{i}(i=1,2, \ldots, m)$, the decision maker is invited to express evaluation or preference 
according to each attribute $c_{j}(j=1,2, \ldots, n)$ by a intuitionistic fuzzy value $q_{i j}=\left(u_{i j}, v_{i j}\right)(i=1,2 \mathrm{~L}, m ; j=1,2, \mathrm{~L}, n)$, Where $u_{i j}$ indicates the hesitant degree that the decision maker considers what the alternative $\alpha_{i}$ should satisfy the criteria $c_{j}, v_{i j}$ indicates the hesitant degree that expert e considers what the alternative $\alpha_{i}$ should not satisfy the criteria $c_{j}$. Then we can obtain a decision making matrix as follow:

$$
D=\left(\begin{array}{cccc}
\mathscr{Q}_{P_{1}} & \mathscr{Q}_{P_{2}} & \mathrm{~L} & \mathscr{Q}_{P_{n}} \\
\mathscr{Q}_{q_{1}} & \mathscr{Q}_{q_{2}} & \mathrm{~L} & \mathscr{Q}_{q_{n}} \\
\mathrm{M} & \mathrm{M} & \mathrm{O} & \mathrm{M} \\
\mathscr{q}_{m 1} & \mathrm{~L} & \mathrm{~L} & \mathscr{Q}_{m n}
\end{array}\right)
$$

Step 2: Utilize Eq. (6) and Eq. (7) to determine the corresponding intuitionistic fuzzy $\mathrm{PIS} A^{+}$and the intuitionistic fuzzy NIS $A^{-}$.

$$
\begin{aligned}
& P_{I S A^{+}}=(\{1\}\{0\}) \\
& N_{I S A^{-}}=(\{0\}\{1\})
\end{aligned}
$$

Step 3: Utilize the intuitionistic fuzzy correlation coefficient to calculate the correlation between the alternative $\alpha_{i}$ and the PISA ${ }^{+}$and the correlation between the alternative $\alpha_{i}$ and the NISA ${ }^{-}$.

$$
\begin{gathered}
\rho_{I F W}\left(A, A^{*}\right)=\frac{C\left(A, A^{*}\right)}{\sqrt{C\left(A, A^{*}\right)} \cdot \sqrt{C\left(A, A^{*}\right)}} \\
\rho^{+}=\frac{\sum_{j=1}^{n} w_{j}\left(u_{A}\left(x_{j}\right)\right)}{\left\{\sum_{j=1}^{n} w_{j}\left[u_{A}^{2}\left(x_{j}\right)+v_{A}^{2}\left(x_{j}\right)\right]\right\}^{\frac{1}{2}}} \\
\rho^{-}=\frac{\sum_{j=1}^{n} w_{j}\left(v_{A}\left(x_{j}\right)\right)}{\left\{\sum_{j=1}^{n} w_{j}\left[u_{A}^{2}\left(x_{j}\right)+v_{A}^{2}\left(x_{j}\right)\right]\right\}^{\frac{1}{2}}}
\end{gathered}
$$

Step 4: Calculate the closeness coefficient of each alternative:

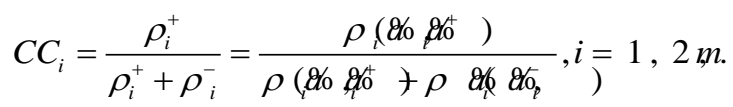

Step 5: Rank all the alternative $a_{i}$ according to the closeness coefficient $C C_{i}$, where the greater the value of the closeness coefficient $C C_{i}$, the better the alternative $a_{i}$.

Step 6: End.

\section{Numerical Example}

In this section, an evaluation problem of information security management is analyzed by the proposed method to demonstrate its applicability and validity.

\subsection{Description of the Efficient Evaluation Problem}

The most often cited reference for which protective measures that comprise good information security is the ISO 17799 standard. The scope of ISO 17799 is to "establish guidelines and general principles for initiating, implementing, maintaining and improving information security management in an organization" [25]. However, it does not provide any instructions on how to achieve an evaluation problem of information security management in a specific company. Then, we take some large state-owned enterprises as an example. A relevant expert from a famous university acts as the decision maker. $\mathrm{He}$ 
chooses five large state-owned enterprises denoted as $a_{1}, a_{2}, a_{3}, a_{4}, a_{5}$. Meanwhile, he identifies four attributes based on the former studies denoted as $c_{1}, c_{2}, c_{3}, c_{4}$ in Table 1 and specifies $w=(0.35,0.25,0.3,0.1)$

Table 1. The Meaning of the Seven Attributes

\begin{tabular}{|l|l|}
\hline Attributes & Meaning \\
\hline$c_{1}$ & $\begin{array}{l}\text { Physical security management } \\
\text { (It includes equipment security management, Environment security } \\
\text { management etc., })\end{array}$ \\
\hline$c_{2}$ & $\begin{array}{l}\text { Operation security management } \\
\text { (It includes operating system maintenance security management, network } \\
\text { maintenance security management, database maintenance security } \\
\text { management etc., }) ;\end{array}$ \\
\hline$c_{3}$ & $\begin{array}{l}\text { Risk management } \\
\text { (It includes environment risk, operation risk, database risk, control risk } \\
\text { etc.,, })\end{array}$ \\
\hline$c_{4}$ & $\begin{array}{l}\text { Human resources and policy management } \\
\text { (It includes human resources management, strategy management, } \\
\text { enterprise's relevant policy management, etc., })\end{array}$ \\
\hline
\end{tabular}

\subsection{Solution to the Evaluation Problem with Novel TOPSIS Method}

As mentioned above, the proposed method which extends the TOPSIS approach with correlation coefficient is introduced to evaluate this five enterprises' information security management. The evaluation model is demonstrated in the Figure 1. 


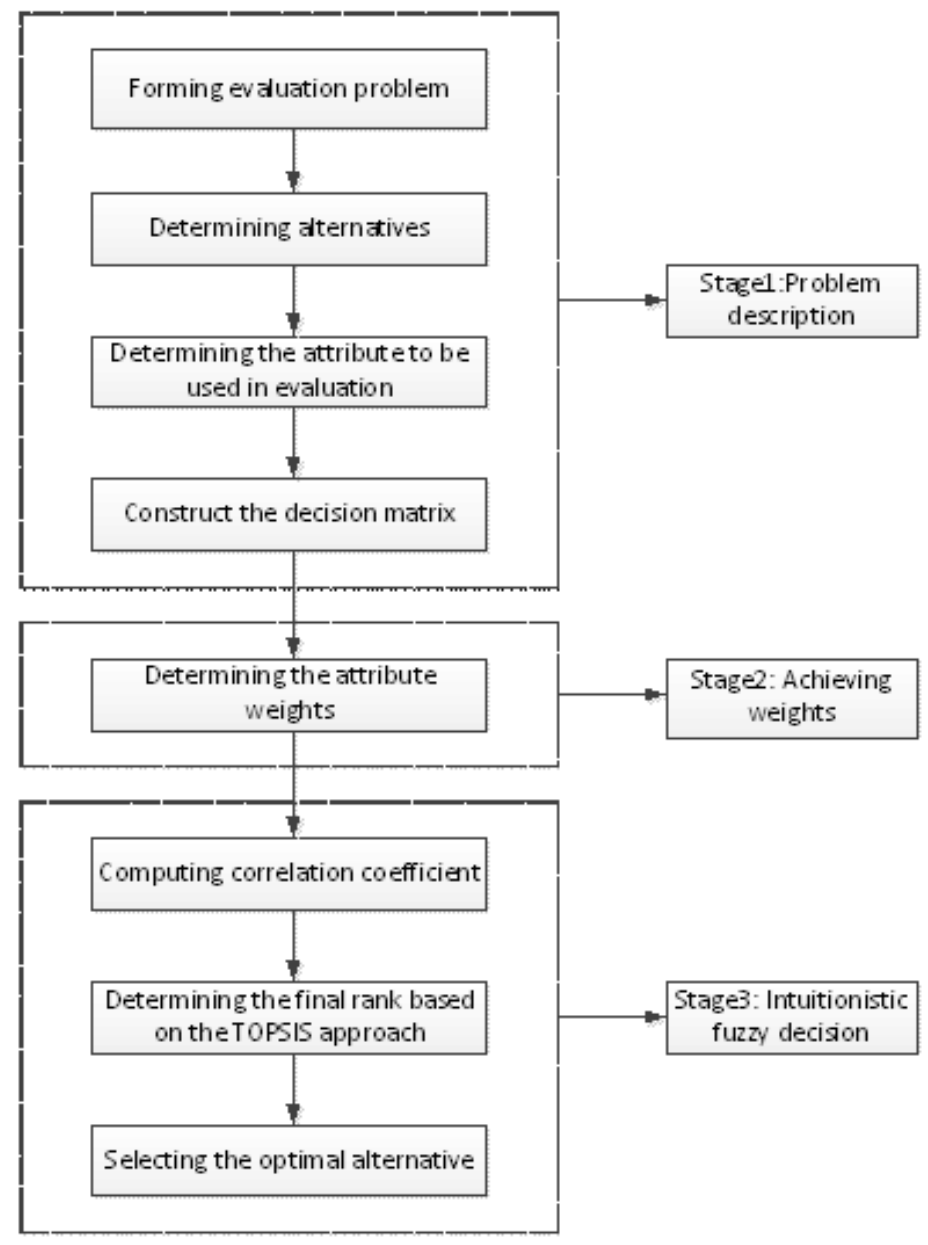

Figure 1. The Evaluation Model of Information Security Management

Based on the evaluation model, the procedure of the decision making problem is as follows:

Step 1: With respect to attribute $c_{j}(j=1,2, \mathrm{~L}, n)$ the evaluation of the alternative $a_{i}(i=1,2, \mathrm{~L}, m)$ is made by an intuitionistic fuzzy value $\mathscr{Z}_{i j}=\left(u_{i j}, v_{i j}\right)(i=1,2, \mathrm{~L}, m ; j=1,2, \mathrm{~L}, n)$. Then we can obtain a decision making matrix as follow:

Table 2. The Transpose of Intuitionistic Fuzzy Decision Matrix

\begin{tabular}{|l|l|l|l|l|l|}
\hline Attributes & \multicolumn{1}{|c|}{$a_{1}$} & $a_{2}$ & $a_{3}$ & $a_{4}$ & $a_{5}$ \\
\hline$c_{1}$ & $\{0.7\}\{0.2\}$ & $\{0.5\}\{0.3\}$ & $\{0.4\}\{0.4\}$ & $\{0.4\}\{0.6\}$ & $\{0.7\}\{0.1\}$ \\
\hline$c_{2}$ & $\{0.6\}\{0.2\}$ & $\{0.5\}\{0.3\}$ & $\{0.3\}\{0.6\}$ & $\{0.5\}\{0.4\}$ & $\{0.6\}\{0.3\}$ \\
\hline$c_{3}$ & $\{0.7\}\{0.1\}$ & $\{0.2\}\{0.7\}$ & $\{0.2\}\{0.6\}$ & $\{0.6\}\{0.2\}$ & $\{0.7\}\{0.3\}$ \\
\hline$c_{4}$ & $\{0.3\}\{0.6\}$ & $\{0.5\}\{0.4\}$ & $\{0.6\}\{0.2\}$ & $\{0.6\}\{0.2\}$ & $\{0.3\}\{0.6\}$ \\
\hline
\end{tabular}

Step 2: The corresponding intuitionistic fuzzy $\mathrm{PISA}^{+}$and the intuitionistic fuzzy NISA ${ }^{-}$ can be acquired:

$$
\operatorname{PISA}^{+}=(\{1\}\{0\})
$$




$$
N I S A^{-}=(\{0\}\{1\})
$$

Step 3: The correlation coefficient between the each alternative $\alpha_{i}$ and the $\mathrm{PISA}^{+}$and between the each alternative $\alpha_{i}$ and the NISA ${ }^{-}$can be calculated:

\section{Table 3. The Correlation Coefficient of Each Alternative}

\begin{tabular}{|l|l|l|}
\hline & $\rho_{i}^{+}$ & $\rho_{i}^{-}$ \\
\hline$a_{1}$ & 0.9161 & 0.3030 \\
\hline$a_{2}$ & 0.6450 & 0.6765 \\
\hline$a_{3}$ & 0.5403 & 0.7902 \\
\hline$a_{4}$ & 0.7575 & 0.5850 \\
\hline$a_{5}$ & 0.8922 & 0.3653 \\
\hline
\end{tabular}

Step 4: Based on the correlation coefficient, the closeness coefficient of each alternative can be obtained:

Table 4. The Closeness Coefficient of Each Alternative

\begin{tabular}{|l|l|}
\hline & $C C_{i}$ \\
\hline$a_{1}$ & 0.7515 \\
\hline$a_{2}$ & 0.4881 \\
\hline$a_{3}$ & 0.4061 \\
\hline$a_{4}$ & 0.5642 \\
\hline$a_{5}$ & 0.7095 \\
\hline
\end{tabular}

Step 5: According to the closeness coefficient $C C_{i}$, the rank-order of all the alternative $a_{i}$ can be demonstrated:

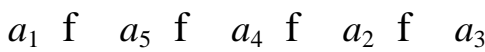

Therefore, we can acquire that the $a_{1}$ is the best enterprise of information security management. In the next step, we can analyze the advantage of $a_{1}$ to improve all the enterprises' information security management.

\subsection{Comparison Analysis with Traditional TOPSIS Approach}

In order to further realize the new approach, we compare this proposed TOPSIS method with the traditional TOPSIS approach. In the traditional TOPSIS approach, step 1 and step 2 is as same as them in the novel method.

Step 3: The Euclidean distance measure between the each alternative $\alpha_{i}$ and the PISA and between the each alternative $\alpha_{i}$ and the NISA $^{-}$can be calculated:

$$
\begin{aligned}
& d_{i j w}\left(Q_{i}, Q 80\right)=\sqrt{\frac{1}{2} \sum_{j=1}^{n} w_{j}\left(\left(u_{i j}-u^{+}\right)^{2}+\left(v_{i j}-v^{+}\right)^{2}\right)} \\
& d_{i f w}\left(g_{i}, Q_{0}\right)=\sqrt{\frac{1}{2} \sum_{j=1}^{n} w_{j}\left(\left(u_{i j}-u^{-}\right)^{2}+\left(v_{i j}-v^{-}\right)^{2}\right)}
\end{aligned}
$$




\section{Table 5. The Euclidean Distance Measure of Each Alternative}

\begin{tabular}{|c|c|c|}
\hline & $d_{i}^{+}$ & $d_{i}^{-}$ \\
\hline$a_{1}$ & 0.2125 & 0.5071 \\
\hline$a_{2}$ & 0.3664 & 0.3512 \\
\hline$a_{3}$ & 0.4138 & 0.3058 \\
\hline$a_{4}$ & 0.3180 & 0.3966 \\
\hline$a_{5}$ & 0.2276 & 0.4883 \\
\hline
\end{tabular}

Step 4: Based on the Euclidean distance measure, the closeness coefficient of each alternative can be obtained:

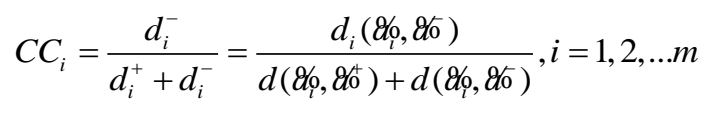

\section{Table 6. The Closeness Coefficient of Each Alternative}

\begin{tabular}{|l|l|}
\hline & $C C_{i}$ \\
\hline$a_{1}$ & 0.7046 \\
\hline$a_{2}$ & 0.4894 \\
\hline$a_{3}$ & 0.4249 \\
\hline$a_{4}$ & 0.5550 \\
\hline$a_{5}$ & 0.6821 \\
\hline
\end{tabular}

Step 5: According to the closeness coefficient $C C_{i}$, the rank-order of all the alternative $a_{i}$ can be demonstrated:

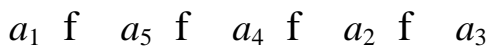

Therefore, we can acquire that the $a_{1}$ is the best enterprise of information security management.

Then, it is obviously that the final result in the traditional approach is as same as the proposed method in this evaluation problem. But the extent of changes between two curves is not quite as same in Figure2. The black line and the red line denote the changes of closeness coefficient with correlation coefficient and closeness coefficient with distance measure, respectively. The extent of changes of the closeness coefficient with correlation coefficient's change is bigger than the extent of changes of closeness coefficient with Euclidean distance measure. So it is easy to compare the alternatives in the TOPSIS approach proposed in this paper, especially there are many complex and similar alternatives. 


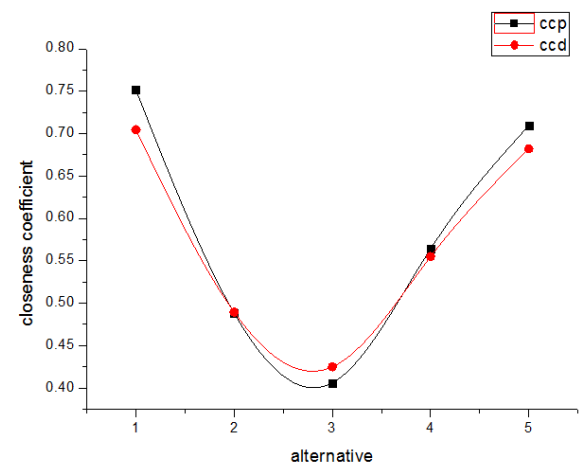

Figure 2. The Comparison between the Propose Method and the Traditional Method

\section{Conclusions}

Because of the inherent vagueness of human preferences, the attributes involved in decision making problems are not always expressed in real numbers, and some are better suited to be denoted by fuzzy values, such as intuitionistic fuzzy values. In this paper, considering membership, non-membership and the uncertainty of the decision maker's preference, we extend the TOPSIS approach with correlation coefficient under intuitionistic fuzzy environment. The contribution of this paper include the following: (1) the design of new evaluation model of information security management under intuitionistic fuzzy environment; (2) the introduction of weighted correlation coefficient of intuitionistic fuzzy set; (3) the creation of new TOPSIS approach with correlation coefficient; and (4) the development of the evaluation problem of information security management; (5) comparison analysis between the new TOPSIS approach and traditional TOPSIS approach in this evaluation model.

Although the proposed method in this paper is a good solution to the evaluation problem of information security management, it cannot analyze more complex problems where many different decision makers take part in this evaluation problem. In the future, we will extend the method to analyze the group decision making problem of information security management.

\section{References}

[1] J. N. Li, "Harbin: Research on information security management metrics", Harbin University of Science and Technology, (2007).

[2] C. C. Huang, K. J. Farn and F. Y. Lin, “A Study on Information Security Management with Personal Data Protection", Proceedings of the International Conference on Parallel and Distributed Systems, Los Alamitos, CA, United States IEEE Computer Society, (2011), pp. 624-630.

[3] J. Bellone, S. Basquiat and J. Rodriguez, "Reaching Escape Velocity: a Practiced Approach to Information Security Management System Implementation", Information Management and Computer Security, vol. 16, 1, (2008), pp. 49-57.

[4] L. A. Zadeh, "Fuzzy sets", Information and Control, vol. 8, (1965), pp. 338-356.

[5] R. R. Yager and D. P. Filer, "Essentials of Fuzzy Modeling and Control”, Wiley, New York, (1994).

[6] D. Dubois and H. Prade, "A review of fuzzy sets aggregation connectives", Information Science, vol. 36, (1985), pp. 85-121.

[7] K. Atanassov, "Intuitionistic fuzzy sets”, Fuzzy Sets and Systems, vol. 20, (1986), pp. 87-96.

[8] K. Atanassov, "New operations defined over the intuitionistic fuzzy sets", Fuzzy Sets and Systems, vol. 61, (1994), pp. 137-142.

[9] K. Atanassov and G. Gargov, "Intuitionistic fuzzy logic", C. R. Acard, Bulgare, Sc., vol. 43, no. 3, (1990), pp. 9-12.

[10] K. Atanassov, G. Pasi and R. Yager, "Intuitionistic fuzzy interpretations of multi-criteria multi-person and multi-measurement tool decision", International Journal of systems Science, vol. 36, (2005), pp. 859-868.

[11] C. Q. Tan and X. H. Chen, "Intuitionistic fuzzy Choquet integral operator for multi-criteria decision making", Expert Systems with Application, vol. 37, (2010), pp. 149-157. 
[12] E. Szmidt and J. Kacprzyk, "Distances between intuitionistic fuzzy sets", Fuzzy Sets and Systems, vol. 114, (2000), pp. 505-518.

[13] Z. S. Xu and R. R. Yager, "Some geometric aggregation operators based on intuitionistic fuzzy sets", International Journal of General Systems, vol. 35, (2006), pp. 417-433.

[14] Z. S Xu, "Intuitionistic fuzzy aggregation operators", IEEE Transaction Fuzzy Systems, vol. 15, (2007), pp. 1179-1187.

[15] F. E. Boran, S. Genc, M. Kurt and D. Akay, "A multi-criteria intuitionistic fuzzy group decision making for supplier selection with TOPSIS method", Expert Systems with Application, vol. 36, (2003), pp. 11363-11368.

[16] C. L. Hwang and K. Yoon, "Multiple Decision Making: Methods and Applications", Springer, Berlin, Heidelberg, New York, (1981).

[17] A. Manish, H. Madasu and B. Kanad, "Choquet Integral vs. TOPSIS: An Intuitionistic Fuzzy Approach", IEEE International Conference on Fuzzy Systems (FUZZ), Hyderabad, INDIA, vol. 7, (2013), pp. 07-10.

[18] G. Kim, C. Park and K. P. Yoon, "Identifying investment opportunities for advanced manufacturing system with comparative-integrated performance measurement", International Journal of Production Economics, vol. 50, (1997), pp. 23-33.

[19] G. R. Janhanshahloo, F. H. Lotfi and M. Izadikhah, "Extension of the TOPSIS method for decision-making problems with fuzzy data", Applied Mathematics and Computation, vol. 181, (2006), pp. 1544-1511.

[20] H. Bustince and P. Burillo, "Correlation of interval-valued intuitionistic fuzzy sets", Fuzzy Sets and Systems, vol. 74, (1995), pp. 237-244.

[21] D. G. Park, Y. C. Kwun, J. H. Park and I. Y. Park, "Correlation coefficient of interval-valued intuitionistic fuzzy sets and itsapplication to multiple attribute group decision making problems", Mathematical and Computer Modelling, vol. 50, (2009), pp. 1279-1293.

[22] P. GrzegorzewskiKendall, "Correlation coefficient for vague preferences”, Soft Compute, vol. 13, (2009), pp. $1055-1061$.

[23] J. Ye, "Multicriteria fuzzy decision-making method using entropy weights-based correlation coefficients of interval-valued intuitionistic fuzzy sets", Applied Mathematical Modelling, vol. 34, (2010), pp. 3864-3870.

[24] J. Ye, "Fuzzy decision-making method based on the weighted correlation coefficient under intuitionistic fuzzy environment", European Journal of Operational Research, vol. 205, (2010), pp. 202-204.

[25] L. Nordstrom, "Assessment of Information Security Levels in Power Communication Systems Using Evidential Reasoning”, IEEE Transactions on Power Delivery, vol. 23, no. 3, (2008), pp. 1384-1391.

\section{Authors}

LI Feng-Quan, (1977), male (Han), born in Hebi City, Henan Province, China. He is a lecturer with master degree, and his mainly research directions are image processing technology and computer network technology. 